\title{
Dental Cavity Lining, Composite Resin and Bioceramic: Randomized Clinical Trial
}

\author{
Simone Silveira de Freitas Pedrosa ${ }^{1}$, Geraldo Magela Salomé ${ }^{2}$, Paulo Roberto Maia ${ }^{3}$, Matheus Henrique \\ Lopes Dominguete ${ }^{4}$, José Dias da Silva Neto ${ }^{* 5}$ \\ ${ }^{1}$ Department: Professional Master's Degree in Applied Health Sciences, Universidade Vale do Sapucaí, Pouso Alegre - \\ MG, Brazil. \\ ${ }^{2}$ Department: Professional Master's Degree in Applied Health Sciences, Universidade Vale do Sapucaí, Pouso Alegre - \\ MG, Brazil. \\ ${ }^{3}$ Department of Biostatistics, University of Vale do Sapucaí, Pouso Alegre - MG, Brazil. \\ ${ }^{4}$ Department: Dental Clinic, Faculty of Dentistry, University of Vale do Rio Verde, Três Corações - MG, Brazil. \\ ${ }^{5}$ Department: Professional Master's Degree in Applied Health Sciences, Universidade Vale do Sapucaí, Pouso Alegre - \\ MG, Brazil.
}

*Corresponding author: José Dias da Silva Neto. Universidade do Vale do Sapucaí. Av. Prefeito Tuany Toledo, 470, Fátima I, Cep. 37554210 - Pouso Alegre, Minas Gerais, Brazil, phone: +55-35-3449923

Received 19 January 2022;

Accepted 10 February 2021;

Published 16 February 2022

\begin{abstract}
Objective: Evaluation of postoperative sensitivity in posterior teeth restored with CIMMO DTA ${ }^{\circledR}$ liner, in composite resin restorations. $\underline{\text { Method: }}$ Randomized, double-blind clinical trial. There were 20 male participants, with an average age of 20 years. Totaling 70 treated teeth, divided into two groups: Group R (Control $n=35$ ), treated with standard restorative procedure. Group D (Study $n=35$ ), treated using CIMMO DTA ${ }^{\circledR}$ cement, as an indirect liner, the assessment was performed by a masked examiner. Sensitivity tests were performed before the restorative procedure, at 48 hours, 7, 15 and 30 days after the procedure. The analysis included the pain caused by thermal stimulation: Cold Test (FT); à Horizontal (TPH) and vertical (TPV) percussion; Bite Test (TM) and Pain Decline Time (DD) is measured. Measured through Visual Analog Scale (EVA). Results: All participants returned for postoperative sensitivity tests. Group D had lower pain sensitivity than group R: on the second day, for TPH with $\mathrm{p}=0.041$; TPV with $\mathrm{p}=0.036$; on the fifteenth day, for TPH with $\mathrm{p}=0.043$; TM $\mathrm{p}=0.021$ and on the thirtieth day, for TF with $\mathrm{p}=0.011$. Conclusion: CIMMO DTA $®$ cement, as an indirect liner in dental restorations, decreased postoperative sensitivity.
\end{abstract}

Keywords: Dental Cavity Lining, Operative Dentistry, Dental Cavity, Pulpar Capping, Dental Materials.

\section{Introduction}

Composite resins for posterior restorations are used, due to the possibility of providing esthetics ${ }^{[1-4]}$. Meta-analysis evaluated the clinical efficacy of posterior resins with nanoparticles, compared to conventional resin. Clinical effects were analyzed, including: absence of postoperative sensitivity and absence of inflammation. There was no difference regarding the type of restoration, type of tooth restored and restoration technique used ${ }^{[3,5,8]}$.

Lining materials are intended to protect the pulp from the adverse effects of dental restorative materials and prevent sensitivity caused by thermal conductivity, by inserting an insulating layer between the restorative material and the remaining tooth structure ${ }^{[6-7]}$.
Currently, for indirect pulp protection, the resin adhesive system itself are considered cavity liners, in addition to: calcium hydroxide-based materials; glass ionomer cements, bioceramic and polymeric materials are also indicated as liners ${ }^{[8]}$.

Posterior composite resins have a thermal conductivity approaching that of tooth structure and are very well tolerated by the pulp. There is evidence that significant adverse reactions may be due to microbial by-products and hydrodynamic fluid flow through the dentinal tubules. It is indicated that: the installation of linings based on calcium hydroxide and glass ionomer significantly shorten the life expectancy of the restoration, due to the fact that these lining materials do not adhere to the tooth structure, allowing greater microleakage $^{[9]}$.

Currently, for indirect pulp protection, the resin adhesive system itself are considered cavity liners, in addition to: calcium 
hydroxide-based materials; glass ionomer cements, bioceramic and polymeric materials are also indicated as liners ${ }^{[8]}$.

Recent studies have determined the development of biological cement with the same base as (Mineral trioxide aggregate) MTA, with the addition of additives (natural elements responsible for increasing the material's strength) and with a biomimetic radiopacifier, in order not to interfere with resistance to masticatory forces. A patent was filed at the National Institute of Industrial Property - INPI, (BR1020170227480) 2017. It is currently marketed by Empresa MJS Ltda ${ }^{[11-13]}$.

CIMMO DTA $®$ cement has physical and biological properties that classify it as a biocompatible material and biomineralization inducer. Attributes that define it as a perspective for material to be used as pulp protection in permanent tooth restorations. The singularities of this cement are the requirements that endorse this proposal: compressive strength, bioactivity that determines ionic bonding with dentin, providing the formation of a dentin/cement monoblock and making the environment inhospitable to microbial proliferation ${ }^{[10-14]}$.

The rationale for this clinical study was to evaluate the minimization of postoperative sensitivity arising from restorative procedures. Use of CIMMO DTA ${ }^{\circledR}$ cement as an indirect pulp protector in composite resin restorations of permanent molars and premolars.

\section{Materials and Methods}

Randomized, double-blind clinical trial (participants and evaluator). Carried out at the Dental Office of the 14th Field Artillery Group - Pouso Alegre (MG), Military Organization of the Brazilian Army in conjunction with the University of Vale do Sapucaí (UNIVÁS), Pouso Alegre (MG), Brazil; from March 23, 2020 to January 18, 2021. The project was approved by the Ethics Committee of UNIVÁS, through the opinion CAAE: 29558620.4.0000.5102 with approval number 3.918. Registered in Clinical Trials NCT04870294. Conducted according to CONSORT guidelines.

265 patients were examined through clinical inspection, using an explorer probe and mouth mirror (SS White ${ }^{\circledR}$, Rio de Janeiro, Brazil). After presenting the study, 120 volunteers agreed to participate, signed the Informed Consent Form and were submitted to specific inclusion and non-inclusion criteria.

The sample size calculation in the present study was defined through previous clinical findings. Among which, a sample of 90 teeth (45 per group) was used, assuming a statistical power of $90 \%$ for detection ${ }^{[15]}$. Considering an expected success rate of $90 \%$ for the treatment with CIMMO DTA $®$, based on studies involving the two cements CIMMO HD $®$ and CIMMO HP ${ }^{\circledR}$ that gave rise to the cement CIMMO DTA ${ }^{[10,11,13,14,16,-19]}$.

A recent study determined that the combined success rate for all restorative treatments using composite resin, with a remnant of 4 to $5 \mathrm{~mm}$ of dentin, was $88.8 \%$, based on 3,012 restorations evaluated: 942 failures ${ }^{[15-20]}$. The final sample of the present study consisted of 70 molar and premolar teeth from 20 participants. All male participants, with an average age of 20 years, members of a Military Institution.

It is noteworthy that the beginning of the clinical procedures in this study coincided with the Covid 19 pandemic. Difficulties occurred due to the sanitary impositions for the execution of the procedures, as well as situations that involved uncertainties, mainly in relation to the patients' autonomy to accept being treated and also to accept participate in the survey.

\section{Non-Inclusion Criteria}

Teeth with cervical caries lesions; participants in orthodontic treatment; affected by systemic diseases (gastroesophageal reflux) or allergies to the materials used; presence of deleterious habits or bruxism; use of a removable denture with forceps on the target tooth; active and untreated periodontal disease; dental mobility; history of prior tooth sensitivity; absence of antagonist tooth; participants who were under treatment of any nature that required continuous use of analgesics or anti-inflammatory drugs. When submitted to the cold sensitivity test, denoted inflammation and necrosis (identification of pain with slow decline and absence of pain, determined non-inclusion).

\section{Inclusion Criteria}

Minimum age of 18 years old; radiographic take for diagnosis of the presence of carious lesion in dentin of premolar or permanent molar; lesion depth and cervical width of at least $1 \mathrm{~mm}$; no pulp exposure; presence of the antagonist, which must be a natural tooth, the same for adjacent teeth; vital pulp and absence of spontaneous painful symptoms; teeth without prior restorative treatment.

\section{Exclusion Criteria}

Participants who did not show up for the post-operative evaluations or who gave up participating in the study after being included. Tested positive for the SARS-Cov-2 virus, without conditions to be evaluated by the required confinement. Participants treated in which the teeth presented, in the postoperative evaluations, the presence of inflammation and necrosis.

\section{Randomization}

The 20 selected participants were randomized through the random.org website. It is important to point out that: the " $n$ " of the study does not refer to participants, but to teeth ${ }^{[15-20]}$.

\section{Sequence of treatments}

Allocation: group R (control: composite resin restoration without lining material); group D (experiment: CIMMO DTA® cement as indirect cavity lining material, followed by composite resin restoration). 70 brown envelopes were made: 35 containing green paper, belonging to group $\mathrm{R}$ and 35 containing pink paper, belonging to group $\mathrm{D}$. A continuity process was established that eliminated the possibility of bias, due to the disposal of the envelopes that were chosen by each participant to each tooth to be treated.

\section{Sensitivity Tests}

Before starting the restorative treatment, an assessment of tooth sensitivity was performed: cold test: Using cotton balls (Cremer $\left.{ }^{\circledR}\right)$, safe in clinical tweezers (Duflex®), cooled with Fluorethane gas (Endo Ice ${ }^{\circledR}$ Spray, Maquira), applied on the buccal surface of the tooth for $15 \mathrm{~s}$ or until the participant indicates a painful sensation (TF). For the cold test, the time from the beginning of the stimulus to its disappearance (time of pain decline) was counted. Percussion test: with the aid of the buccal mirror handle (Duflex $\left.{ }^{\circledR}\right)$, the tooth was touched with light "taps", in the occlusal-apical (TPH) and buccolingual/vestibular-palatal (TPV) directions. Masticatory forces test (MT): Participant performed masticatory movements under a bite device (Indusbello®, Londrina, PR, Brazil). The time of pain decline (DD) was counted from 1 to 3 : (1) for decline $<10$ seconds; (2) for decay (between 10>30 seconds) and (3) for decay (>30 seconds). The participant's perceptions of sensitivity were checked on a scale from 0 to 10 . The scores determined were: 0 no pain, 1 to 2 mild pain, 3 to 5 moderate pain, 6 to 7 moderate pain a 
little worse, 8 to 9 severe pain, 10 maximum pain. Visual Analog Scale (VAS) ${ }^{[21]}$ was used.

\section{Restorative Procedures}

Initially, pumice prophylaxis (SS White ${ }^{\circledR}$, Rio de Janeiro, RJ, Brazil) and water were performed in order to remove residues and/or dental biofilm. Proceeding to the stage of topical anesthesia (Benzotop® 200mg, DFL, Jacarepaguá, RJ, Brazil), followed by local infiltrative anesthesia (Alphacaine ${ }^{\circledR} 2 \%$ DFL, Jacarepaguá, RJ, Brazil) and absolute isolation of the operative field. Salienta-se que o isolamento absoluto foi realizado anteriormente ao preparo cavitário, seguindo as normas sanitárias (Covid 19), para contenção de aerossóis provocados pela utilização da alta rotação.

The surgical procedure was initially performed with spherical diamond tips $\left(\mathrm{KG}^{\circledR}\right.$ Sorensen, Cotia, SP, Brazil) with a number compatible with the carious lesion $(1011,1012,1013$, 1014, 1016). Then, spherical carbide steel drills, numbering compatible with the lesion, no. 2, 4 or 6 (KG Sorensen ${ }^{\circledR}$, Cotia, SP, Brazil) were used at low speed (Contra angle, Kavo®, Joinville, PR, Brazil) to remove the carious tissue. For restorations that needed to reestablish the shape of the proximal walls, wedges, preformed metal matrices and staples (Unimatrix ${ }^{\circledR}$, TDV Pomerode-SC-Brasil) were used.

For teeth in group R: etching was performed with $37 \%$ phosphoric acid (Condac $® 37$, FGM, Joinville, SC, Brazil) for 30 seconds in enamel and $15 \mathrm{~s}$ in dentin. Then, the cavity was washed with the aid of a triple syringe, using a jet of air/water, for 10 seconds.

The cavities received the restorative system composed of the adhesive (Adper Single Bond 2®, 3M ESPE Dental Products TM, St. Paul, MN, USA) and the nano-particulate resin (Filtek Z350XT®, 3M ESPE Dental Products TM, St. Paul, MN, USA). The dentin substrate was left slightly moist, with the aid of cotton balls (Cremer®). The adhesive material was used, by means of a micro brush (Cavibrush ${ }^{\circledR}$, FGM, Joinville, SC, Brazil), strictly following the manufacturer's standards, used for this purpose; saturated for each covering, two consecutive layers of adhesive were applied to enamel and dentin, waited for 30 seconds, continued with light jets of air for 5 seconds and then photo activation was performed for 10 seconds with LED (Poly® Wireless, Kavo Joinville-SC-Brasil), with a power of $600 \pm 50$ $\mathrm{mW} / \mathrm{cm}^{2}$.

The restorations were performed using composite resin (Filtek Z350 XT®, 3M ESPE Dental Products TM, St. Paul, MN, USA) using the oblique incremental technique, in increments of at most $2 \mathrm{~mm}$ in thickness, and each increment was light cured. for 20 seconds, with LED (Poly® Wireless, Kavo, Joinville, SC, Brazil) final polymerization for $40 \mathrm{~s}$.

After completion of the restorations, the absolute isolation was removed, then the sculpture was refined and occlusal adjustment, immediate finishing with fine diamond tips number 2135F, 3118F and 3195F (KG Sorensen ${ }^{\circledR}$, Cotia, SP, Brazil), depending on of the restored anatomical region. Polishing was performed with abrasive silicone polishers for resins (Microdont ${ }^{\circledR}$, Camanducaia, SP-Brazil) in medium (yellow) and superfine (white) grains and felt disk (Diamond $\left.{ }^{\circledR}, \mathrm{FGM}\right)$ with diamond paste (Diamond Excel®, FGM, Joinville, SC, Brazil).

In group $\mathrm{D}$ teeth, the same restorative step was performed, but prior to the acid etching step, CIMMO DTA® Cement was applied as a base for lining the dental cavity, following the manufacturer's instructions.

CIMMO DTA® Cement was handled in a sterilized glass plate and spatula 24 (Duflex®), a portion of cement powder and a drop of distilled water were dispensed (1:1 ratio). Then, the manipulated material was inserted, with the aid of a dentin spoon (Duflex ${ }^{\circledR}$ ), in the pulp wall of the cavity preparation. Using clinical forceps (Duflex $\left.{ }^{\circledR}\right)$ and cotton balls (Cremer $\left.{ }^{\circledR}\right)$, the cement was condensed at the bottom of the cavity, obtaining adaptation. Then, acid etching, adhesive application, restorative technique and polishing were carried out as previously recommended for the $\mathrm{R}$ group.

Clinical evaluations. Research participants had their personal records, anamnesis, as well as the type of proposed treatment entered in a clinical record. However, only the operator, who performed the restorative procedures, had access to the forms. Periapical radiographs were taken, preoperatively and 30 days after the operation. In another form, the values obtained in the sensitivity tests at 5 different times were recorded. The first tests, carried out in the preoperative period and the others in the postoperative period. The assessments were performed by a single examiner, trained by the researcher and not involved in restorative procedures. The assessments were recorded in a separate form. The examiner was kept blind for all assessments.

Sensitivity tests were performed before the restorative procedure, at 48 hours, 7, 15 and 30 days after the procedures ${ }^{[22]}$. The analysis included: pain caused by thermal stimuli, percussion and bite; as described in the paragraph (sensitivity test).

\section{Statistical Analysis}

Data were tabulated in Microsoft Excel 2016 and submitted to statistical analysis. Minitab version 19.1 and Statistical Package for Social Sciences, inc. (SPSS) Chicago, USA, version 26.0. The level of significance was $5 \%(\mathrm{p}<0.05)$. The following tests were applied: Anderson-Darling normality; Mann-Whitney; T-Student; Friedman and Dunnett.

\section{Results and Discussion}

35 teeth were allocated to each group. 46 molars and 24 premolars from 20 patients. All patients returned for post-operative evaluations. There were no losses (Figure 1).

As for the Mann-Whitney Test. Group D had lower sensitivity regarding: $(\mathrm{TPH}) \mathrm{p}=0.041$ and (TPV) $\mathrm{p}=0.036$ for the second postoperative day. Postoperative on the 15th day: (TPH) $\mathrm{p}=0.043$ and $(\mathrm{TM}) \mathrm{p}=0.021$. Thirtieth postoperative day, $(\mathrm{TF}) \mathrm{p}=$ 0.011 (Table 1).

As for the Dunnett Test. The results were significant for group $\mathrm{D}$ in: $(\mathrm{TM})$ on days: $7 \mathrm{p}=0.022 ; 15 \mathrm{p}=0.005$ and $30 \mathrm{p}=0.005$. (TF) on the 30th day $\mathrm{p}=0.001$ and for the time of pain decline (DD) on days $15, \mathrm{p}=0.003$ and $30 \mathrm{p}=0.003$ (Table 2). 


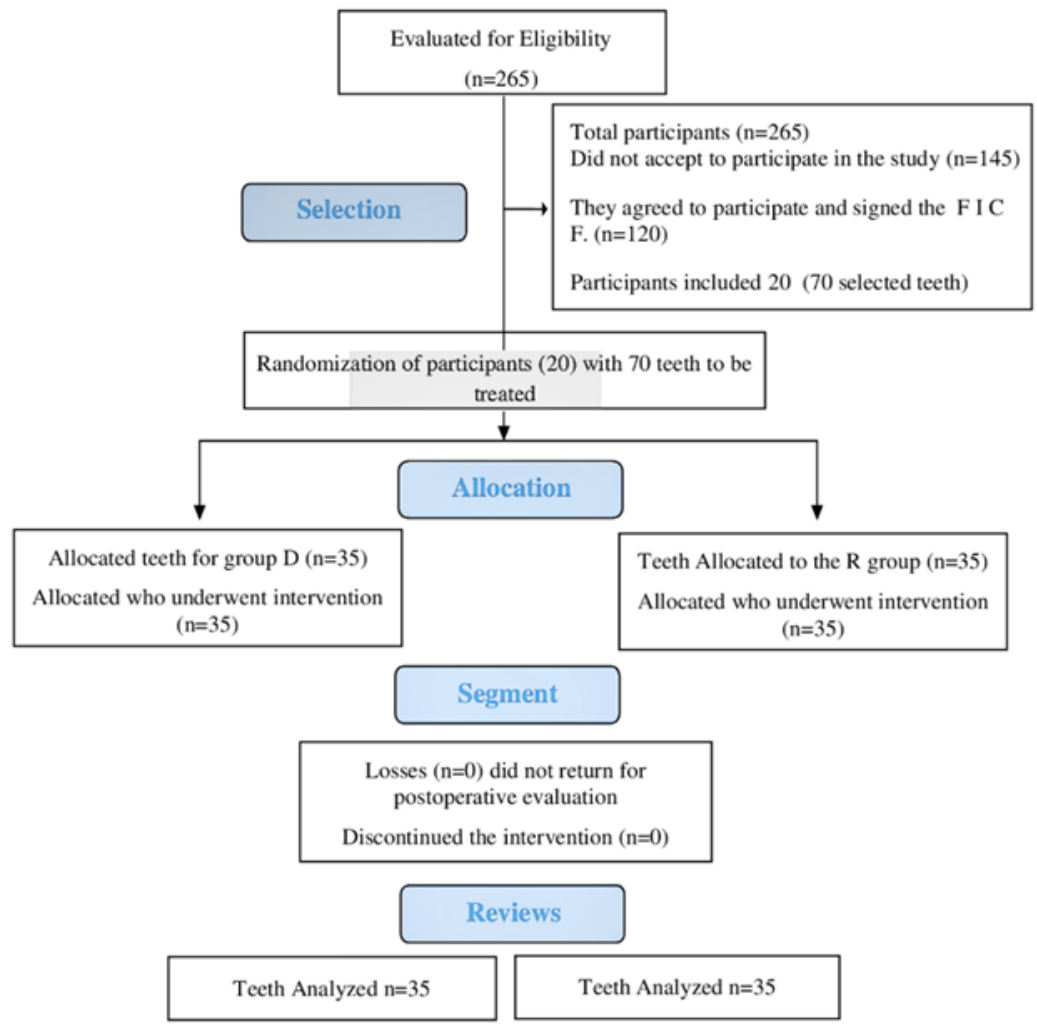

Figure1 - CONSORT Diagram of Study Participants Flow

Table 1- Mann-Whitney test: Statistical analysis between the two groups (D and R), for the same type of test and day of its performance. Referred to as: preoperative and postoperative days: (2, 7,15 and 30).

\begin{tabular}{|c|c|c|c|c|c|c|c|c|c|c|}
\hline & \multicolumn{2}{|c|}{ PREOPERATIVE } & \multicolumn{2}{|l|}{$2^{\circ}$. DAY } & \multicolumn{2}{|l|}{$7^{\circ}$. DAY } & \multicolumn{2}{|c|}{$15^{\circ}$. DAY } & \multicolumn{2}{|c|}{ 30'. DAY } \\
\hline Test & $\begin{array}{l}\text { P- } \\
\text { VALUE }\end{array}$ & $\begin{array}{l}\text { Statistical } \\
\text { difference } \\
\text { for } \\
\text { analyzed } \\
\text { groups }\end{array}$ & $\begin{array}{l}\text { P- } \\
\text { VALUE }\end{array}$ & $\begin{array}{l}\text { Statistical } \\
\text { difference } \\
\text { for } \\
\text { analyzed } \\
\text { groups }\end{array}$ & $\begin{array}{l}\text { P- } \\
\text { VALUE }\end{array}$ & $\begin{array}{l}\text { Statistical } \\
\text { difference } \\
\text { for } \\
\text { analyzed } \\
\text { groups }\end{array}$ & $\begin{array}{l}\text { P- } \\
\text { VALUE }\end{array}$ & $\begin{array}{l}\text { Statistical } \\
\text { difference } \\
\text { for } \\
\text { analyzed } \\
\text { groups }\end{array}$ & $\begin{array}{l}\text { P- } \\
\text { VALUE }\end{array}$ & $\begin{array}{l}\text { Statistical } \\
\text { difference } \\
\text { for } \\
\text { analyzed } \\
\text { groups }\end{array}$ \\
\hline TPH & 0,174 & $\mathrm{D}=\mathrm{R}$ & 0,041 & $\mathrm{D}<\mathrm{R}$ & 0,865 & $\mathrm{D}=\mathrm{R}$ & 0,043 & $\mathrm{D}<\mathrm{R}$ & 0,362 & $\mathrm{D}=\mathrm{R}$ \\
\hline TPV & 0,833 & $\mathrm{D}=\mathrm{R}$ & 0,036 & $\mathrm{D}<\mathrm{R}$ & 0,157 & $\mathrm{D}=\mathrm{R}$ & 0,125 & $\mathrm{D}=\mathrm{R}$ & 0,255 & $\mathrm{D}=\mathrm{R}$ \\
\hline TM & 0,964 & $\mathrm{D}=\mathrm{R}$ & 0,155 & $\mathrm{D}=\mathrm{R}$ & 0,123 & $\mathrm{D}=\mathrm{R}$ & 0,021 & $\mathrm{D}<\mathrm{R}$ & 0,293 & $\mathrm{D}=\mathrm{R}$ \\
\hline $\mathrm{TF}$ & 0,537 & $\mathrm{D}=\mathrm{R}$ & - & - & 0,727 & $\mathrm{D}=\mathrm{R}$ & 0,976 & $\mathrm{D}=\mathrm{R}$ & 0,011 & $\mathrm{D}<\mathrm{R}$ \\
\hline DD & 0,955 & $\mathrm{D}=\mathrm{R}$ & 0,866 & $\mathrm{D}=\mathrm{R}$ & 0,735 & $\mathrm{D}=\mathrm{R}$ & 1 & $\mathrm{D}=\mathrm{R}$ & 1 & $\mathrm{D}=\mathrm{R}$ \\
\hline
\end{tabular}

Table 2: Dunnett Test: Analysis of responses to clinical sensitivity tests performed in groups (D and R). Compares the same group on days $(2,7,15$ and 30$)$ having as a parameter the responses obtained in the preoperative tests

\begin{tabular}{|c|c|c|c|c|c|c|c|c|c|c|}
\hline \multicolumn{11}{|c|}{ TEST DUNNETT } \\
\hline \multirow[t]{2}{*}{ Day } & \multicolumn{5}{|c|}{ Group D } & \multicolumn{5}{|c|}{ Group R } \\
\hline & TPH & TPV & TM & $\mathrm{TF}$ & DD & TPH & TPV & $\mathrm{TM}$ & $\mathrm{TF}$ & DD \\
\hline 2 & 0,985 & 0,982 & 0,143 & 1 & $\mathrm{O}, 685$ & 1 & 0,366 & 0,730 & 0,529 & 0,995 \\
\hline 7 & 0,765 & 0,473 & 0,022 & 0,700 & 0,125 & 0,539 & 0,979 & 0,949 & 0,996 & 0,408 \\
\hline 15 & 0,326 & 0,241 & 0,005 & 0,153 & 0,003 & 0,329 & 1 & 0,996 & 0,870 & 0,075 \\
\hline 30 & 0,326 & 0,198 & 0,005 & 0,001 & 0,003 & 0,178 & 0,884 & 0,820 & 0,914 & 0,075 \\
\hline
\end{tabular}

The purpose of this study was to assess the sensitive response; before and after carrying out a restorative treatment using CIMMO DTA ${ }^{\circledR}$ Cement, as a lining, in indirect posterior restorations compared to standard restorative procedures.

The clinical study was randomized, double-blind, as it offered the necessary evidence to propose a new clinical protocol ${ }^{[23]}$. Clinical studies in dentistry can provide group analysis: tests and control, with standardization of samples based on teeth, using a smaller number of participants ${ }^{[23]}$.

The method used for sensitivity analysis was the Visual Analogue Scale (VAS), which has been used in this type of clinical trial, as it enables the study of the evolution of pain in the participants ${ }^{[24]}$. The absence of statistical difference between the studied groups for responses to preoperative sensitivity tests allowed us to emphasize the homogeneity of the samples. 
According to the results of this study, the highest means of sensitivity were found in the first 48 hours after the restorative procedure in group $\mathrm{R}$. When evaluating the evolution of pain, it was observed that group D showed considerable decline, with less sensitivity than group R, for TPH and TPV tests.

On the seventh postoperative day, there was no statistical difference between the groups. However, on the fifteenth day, group D showed less sensitivity to TPH and TM. On the thirtieth day of follow-up, there was no statistical difference between the tests performed for the two groups, with the exception of TF, in which group D had lower sensitivity than group $\mathrm{R}$.

When performing statistical analysis using the Dunnett Test, the responses to the tests of sensitivity and time and pain decline for each group, using the preoperative results as a parameter, significant responses were obtained for group D on days: 7, 15 and 30 referring to the bite test (TM); on the 30th day for the cold test (TF) and on the 15th and 30th day for the time of pain decline (DD). The $\mathrm{R}$ group did not present a statistically significant difference for the aforementioned analysis.

Dentin, the dental tissue involved in the present study, when receiving chemical, thermal and tactile stimuli, determines sensitive responses, interpreted by pain ${ }^{[23]}$. Such reaction can be explained by the hydrodynamic theory of Brännström, M. (1966). The dentinal canaliculi harbor tissue fluid from the pulp. The movement of these liquids in the canaliculi and the pressure established by external stimuli are directly responsible for signaling to neuronal receptors, which decode such changes as sensory responses (pain). Thus, dentin and pulp are considered: dentin-pulp complex. All actions performed on the dentin are reflected in the Pulp ${ }^{[23]}$.

Studies performed on human teeth have shown adverse pulp effects. They are mainly represented by the induction of persistent chronic inflammatory response, and absence of tissue repair, established as a response to the transdentinal diffusion of toxic components from adhesive systems, mainly by 2hydroxyethyl methacrylate (HEMA) and triethylene glycol dimethacrylate (TEGDMA), coming from the systems stickers. Direct or indirect contact of toxic components with pulp cells are considered foreign bodies and trigger an inflammatory reaction mediated by macrophages ${ }^{[24]}$.

The present study evaluated the teeth treated by both groups. Follow-up was performed on the second postoperative day, which determined the significance of the absence of pain, for group D (DTA® cement), in relation to the tests: horizontal and vertical percussion. There was also a relative significance to the horizontal percussion tests and bite test, on the fifteenth day. Absence of pain for teeth treated in group D (DTA® cement). However, the results that bring greater response in relation to the presence or absence of hyperemia in treated teeth were in relation to the cold sensitivity test. On the thirtieth day of evaluation, treated teeth in group D (DTA® cement) showed responses that indicate vitality (rapid decline pain). There was significance regarding this test for group D (DTA ${ }^{\circledR}$ cement). This discussion corroborates studies ${ }^{[24-25]}$.

The authors' hypothesis ${ }^{[24-25]}$ in relation mainly to the chemical components of dentin adhesives indicates the possible detection of vitality (rapid decline pain) in treated teeth in group D, on the thirtieth day; absence of pain in the horizontal and vertical percussion tests, on the second day, as well as absence of pain in the horizontal and bite percussion tests, on the fifteenth day of analysis. The presence of DTA ${ }^{\circledR}$ cement, in the teeth in question, in the pulp wall of the cavities, could be responsible for the absence of pain in the tests, at the times determined by the study.
The advent of biological cements signaled a new era in dentistry. These cements are biocompatible and bioactive alternatives for use in procedures where the conventional technique is limited ${ }^{[10-12]}$. Bioactive cements do not have toxic components in their constitutions, such as those found in HEMA and TEGDMA adhesive systems ${ }^{[24-25]}$.

Recent studies have determined the development of biological cement with the same base as MTA (Mineral Trioxide Aggregate) and Biodentine ${ }^{\circledR}$, used in Endodontics and considered bioactive, as they provide ionic bonding with dentin, regenerating the dentin tissue, establishing themselves as a base, previous to composite resin restoration, preventing the negative action of adhesive systems that, in conventional techniques, are installed directly on the pulp walls of cavity preparations ${ }^{[10-12,14]}$.

The DTA $®$ cement was created from the endodontic cements CIMMO $\mathrm{HP}{ }^{\circledR}$ and $\mathrm{CIMMO} \mathrm{HD} \AA$, the first endodontic obturator and the second, root perforation repair. The composition of the DTA ${ }^{\circledR}$ cement was established by joining components of $\mathrm{HP} \circledast$ and $\mathrm{HD} \AA$, which provided the possibility of obtaining putty consistency (ready to use), providing the possibility of installation in dentinal cavities, proposed in this study and also for presenting radiopacity, a requirement for liner cements.

The idea for proposing such cement arose from the results obtained in a pediatric clinical study that used CIMMO HD® cement as a regenerator of deciduous teeth submitted to pulpotomies. The results of this study showed that the rehabilitation occurred due to the cement's properties: biocompatibility and bioactivity. CIMMO HD® was considered an option to be used as a single element in pulpotomies of primary teeth $^{[12]}$.

Indirect pulp protections represent the application of liner sealing agents and/or protective bases on the cavity walls, in order to protect the dentin/pulpal complex from different types of injuries: maintain pulp vitality; inhibit the carious process; reduce microleakage and stimulate the formation of reactive and/or restorative sclerotic dentin ${ }^{[24-25]}$. The studied cement provided possibilities to be used as a liner or base in restorations of teeth damaged by caries, which present vitality.

The limitations of the present study are defined by the fact that it was carried out during the Covid 19 pandemic. The perspectives of the present study are: continuation of the proservations of treated teeth and the possibility, after the pandemic, of carrying out a new study with a larger sample size. Given that the cement CIMMO DTA $®$ cement, as an indirect liner in dental restorations, decreased postoperative sensitivity.

\section{Conclusion}

CIMMO DTA ${ }^{\circledR}$ cement, as an indirect liner in dental restorations, decreased postoperative sensitivity.

\section{Ethics approval and consent to participate}

The project was approved by the Ethics Committee of UNIVÁS, through the opinion CAAE: 29558620.4.0000.5102 with approval number 3.918 .

\section{List of abbreviations}

$\mathrm{TPH}=$ Horizontal Percussion Test

$\mathrm{TPV}=$ Vertical Percussion Test

$\mathrm{TM}=$ Bite Test

$\mathrm{TF}=$ Cold test 
DD = Pain Decline Time

$\mathrm{EVA}=$ Visual Analog Scale

UNIVÁS = University of Vale do Sapucaí

$\mathrm{MG}=$ Minas Gerais state

$\mathrm{D}=$ Group $\mathrm{D}$

$\mathrm{R}=$ Group $\mathrm{R}$

MTA $=$ Mineral trioxide aggregate

CAAE $=$ Certificate of Presentation of Ethical Appreciation

HEMA = 2-hydroxyethyl methacrylate

TEGDMA = triethylene glycol dimethacrylate

\section{Data Availability}

Readers of the article will be able to access the data underlying the study results, through the registration link in Clinical Trials NCT04870294

(https://register.clinicaltrials.gov/prs/app/action/SelectProtocol?sid $=$ S000ARHB \&selectaction $=$ Edit\&uid $=$ U0003JVY \&ts $=2 \& \mathrm{cx}=8 \mathrm{ok}$ uhx).

\section{Conflicts of Interest}

The author(s) declare(s) that there is no conflict of interest regarding the publication of this paper.

\section{Funding Statement}

This research did not obtain funding for its structuring. The publication of the article will be financed by the authors.

\section{Authors' contributions}

1) SS: performed the clinical procedures, collected research data and followed the evaluations. He was also responsible for the initial writing of the article.

2) GM: co-supervisor of the work, assisted in the interpretation of data and writing of the article.

3) PR: statistician responsible for calculating the sample size and statistical analysis of the study.

4) $\mathrm{MH}$ : assisted in the interpretation of data and writing of the article.

5) JD: work advisor. He followed the project structuring process, submission to the Brazil platform (ethics committee), submission to the clinical trials. gov, followed the data collection, statistical analysis, correction and adaptation of the article for submission and is the corresponding author of this submission.

All authors read and approved the final manuscript.

\section{Acknowledgments}

The authors are grateful for the contribution of MJS Ltda for providing the cement for the study.

\section{References}

[1] B. M. Maran, J. L. de Geus, M. F. Gutiérrez, et. al, "Nanofilled/nanohybrid and hybrid resin-based composite in patients with direct restorations in posterior teeth: A systematic review and meta-analysis," J Dent, vol. 99, no. 103407, pp.1-16, 2020.
[2] M. G. Rasines Alcaraz, A. Veitz-Keenan, et. al, "Direct composite resin fillings versus amalgam fillings for permanent or adult posterior teeth," Cochrane Database Syst Ver, vol. 31, no. 3, pp. 1-62, 2014.

[3] H. Alzraikat, M. Burrow, G. Maghaireh, N. Taha, "Nanofilled resin composite properties and clinical performance: A review", Oper Dent, vol. 43, no. 4, pp. 173-190, 2018.

[4] D. Angerame, M. De Biasi, "Do nanofilled/nanohybrid composites allow for better clinical performance of direct restorations than traditional microhybrid composites? A systematic review", Oper Dent, vol. 43, no. 4, pp. 191209, 2018.

[5] H. L. Arbildo-Vega, B. Lapinska, S. Panda, C. LamasLara, A. S. Khan, M. Lukomska-Szymanska, "Clinical Effectiveness of Bulk-Fill and Conventional Resin Composite Restorations: Systematic Review and MetaAnalysis", Polymers (Basel), vol. 10, 12, no. 8, pp. 1-51, 2020.

[6] A. Sharma, M. S. Thomas, N. Shetty, N. Srikant, "Evaluation of indirect pulp capping using pozzolanbased cement (ENDOCEM-Zr ${ }^{\circledR}$ ) and mineral trioxide aggregate - A randomized controlled trial", J Conserv Dent, vol. 23, no. 2, pp. 152-157, 2020.

[7] C. Peskersoy, J. Lukarcanin, M. Turkun, "Efficacy of different calcium silicate materials as pulp-capping agents: Randomized clinical trial", J Dent Sci, vol. 16, no. 2, pp. 723-731, 2021.

[8] M. A. Petrou, F. A. Alhamoui, A. Welk, et. al, "A randomized clinical trial on the use of medical Portland cement, MTA and calcium hydroxide in indirect pulp treatment", Clin Oral Investig, vol. 18, no. 5, pp. 1383-9, 2014.

[9] A. B. Schenkel, A. Veitz-Keenan, "Dental cavity liners for Class I and Class II resin-based composite restorations", Cochrane Database Syst Ver, vol.5, 3, no. 3, pp. 1-38, 2019.

[10] S. R. Silva, J. D. Silva Neto, T. B. Schnaider, et. al, "The use of a biocompatible cement in endodontic surgery. A randomized clinical trial", Acta Cir. Bras, vol. 31, no. 6, pp. 422-7, 2016.

[11] R. M. L. Boczar, D. F. Veiga, Y. Juliano, T. B. Schnaider, J. D. Silva Neto, "Bioceramic cement in endodontic fillings: a randomized clinical trial", J Dent Health Oral Disord Ther, vol. 11, no. 3, pp. 78-84, 2020.

[12] F. V. Moysés, D. F.Veiga, M. J. Pereira, et. al, "Bioactive and biocompatible cement as a single element in pulpotomy of deciduous teeth: a randomized clinical trials", Rev Gaúch Odontol, vol. 68, no. 1, pp. 1-8, 2020.

[13] J. D. Silva Neto, T. B. Schnaider, A. Gragnani, et. al, "Portland cement with additives in the repair of furcation perforations in dogs," Acta Cir Bras, vol. 27, no. 11, pp. 809-814, 2012.

[14] C. C. Zerbinatti, D. F. Veiga, M. A. B. Oliveira, et. al, "Bioceramic cement in the filling of bone defects in rats," Acta Cir Bras, vol. 34, no. 6, pp. 1-7, 2019.

[15] A. F. Soares, A. C. S. Pinto, "Taxa de sucesso de restaurações com resina composta bulk-fill: Revisão de literatura," Id on Line Rev Mult Psic, vol. 13, no. 47, pp. 397-409, 2019.

[16] J. D. Silva Neto, R. H. Brito, T. B. Schnaider,et. al, "Root perforations treatment using mineral trioxide 
aggregate and Portland cements," Acta Cir Bras, vol. 25, no. 6, pp. 479-84, 2010.

[17] S. R. Silva, J. D. Silva Neto, D. F.Veiga, T. B. Schnaider, L. M. Ferreira, "Portland cement versus MTA as a root-end filling material. A pilot study," Acta Cir Bras, vol. 30, no. 2, pp. 160-4, 2015.

[18] M. D. S. Pedrosa, T. Alves, F. N. Nogueira, M. Holzhausen, C. R. Sipert, "Cytotoxicity and cytokine production by calcium silicate-based materials on periodontal ligament stem cells," Braz Dent J, vol. 32, no. 3, pp. 65-74, 2021.

[19] S. R. Silva, I. J. Z. Filho, J. D. Silva Neto, "Incomplete rhizogenesis and necrosis treated with CIMMO $\mathrm{HP}^{\circledR}$ cement synthetic barrier: case report," J Dental Health Oral Disord Ther, vol. 9, no. 3, pp. 205-8, 2018.

[20] N. Alvanforoush, J. Palamara, R. H. Wong, M. F. Burrow, "Comparison between published clinical success of direct resin composite restorations in vital posterior teeth in 1995-2005 and 2006-2016 periods," Aust Dent J, vol. 62, no. 2, pp. 132-45, 2017.

[21] J. C. C. Nascimento, Amaral, M. T. A. Calasans, "Avaliação da dor em paciente com câncer em cuidados paliativos à luz da literatura," Saúde \& Ciência em Ação, vol. 3, no. 1, pp. 11-26, 2017.

[22] C. R. G. Torres, M. C. Mailart, R. S. Rocha, et. al, "The influence of a liner on deep bulk-fill restorations: Randomized clinical trial," J Dent, vol. 102, no. 103454, pp. 1-8, 2020.

[23] D. Hickey, O. Sharif, F. Janjua, P.A. Brunton, "Bulk dentine replacement versus incrementally placed resin composite: A randomised controlled clinical trial," $J$ Dentistry, vol. 46, pp. 18-22, 2016.
[24] N. Scotti, G. Cavalli, M. Gagliani, L. Breschi, "New adhesives and bonding techniques. Why and when," Int $J$ Esthet Dent, vol. 12, no. 4, pp. 524-535, 2017.

[25] M. G. Santiago, A. L. Gomes-Cornélio, L. A. de Oliveira, M. Tanomaru-Filho, L. P. Salles, "Calcium silicate-based cements cause environmental stiffness and show diverse potential to induce osteogenesis in human osteoblastic cells," Sci Rep, vol. 18, no. 1, pp. 1-11, 2021.

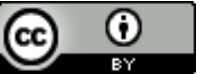

Open Access This article is licensed under a Creative Commons Attribution 4.0 International License, which permits use, sharing, adaptation, distribution and reproduction in any medium or format, as long as you give appropriate credit to the original author(s) and the source, provide a link to the Creative Commons license, and indicate if changes were made. The images or other third party material in this article are included in the article's Creative Commons license, unless indicated otherwise in a credit line to the material. If material is not included in the article's Creative Commons license and your intended use is not permitted by statutory regulation or exceeds the permitted use, you will need to obtain permission directly from the copyright holder. To view a copy of this license, visit https://creativecommons.org/licenses/by/4.0/.

(C) The Author(s) 2021 